\title{
Discussion: TBM performance through the engineering geology of the Lee Tunnel
}

Tim Newman BSc, MSc, PhD, DIC, EurGeol, FGS, CEng, MIMMM Geotechnical Engineer, CH2M Hill; formerly Thames Water Utilities Ltd, London, UK (corresponding author: tim.newman@ch2m.com)

Matthew Bellhouse BSc, CGeol, FGS

Geotechnical Manager, J. Murphy \& Sons Limited, London, UK

John Corcoran BSC, CEng, MICE

Tunnel and Enabling Works Manager, Morgan Sindall, Warwickshire, UK
Richard Sutherden BEng, CEng, FICE

Head of Engineering (South), J. Murphy \& Sons Limited, London, UK

Rafik Karaouzene BSC

Civil Engineer, Vinci Construction Grand Projets, London, UK

James Nicholas Shirlaw

Golder Associates (Hong Kong) Ltd.

\section{Contribution by J. N. Shirlaw}

The authors present an extremely interesting paper on the driving of the Lee Tunnel (Newman et al., 2016), including the key tunnel-boring machine (TBM) parameters for the whole of the drive (Figure 11). Busy Lizzie certainly lived up to her name, based on the high advance rates that were consistently achieved.

Some key details of the TBM are not provided in the paper; these details would provide important context for the material presented, and include

- the excavated diameter (only the internal diameter of the lining is provided)

n the limiting torque on the cutterhead

- the limiting maximum thrust

- the ring length: reference is made to ring numbers within the paper, but without the ring length the relevant locations cannot be related to the other figures.

The first two of these items are available, for now, on the Herrenknecht website. This gives the TBM diameter as $8.85 \mathrm{~m}$ and the maximum torque as $8597 \mathrm{kNm}$.

The authors state that (Newman et al., 2016)

The two TBM parameters that reveal most about the strength of the ground in the tunnel face are the disc cutter penetration in millimetres per cutter wheel revolution (the 'step' or depth of cut) and front contact force $(\mathrm{kN})$ with the ground in the tunnel face.

The authors would be correct if the tunnel had been advanced in moderately strong or stronger rock. In such rock, the discs will break the rock into chips, as illustrated in Bruland (2000). The equations summarised in Rostami et al. (1996) can then be used to relate the strength of the rock to the advance per revolution, the disc size and configuration, and the force applied per disc.

However, in the weak chalk, the primary cutting action would have been by the action of the picks, excavating the ground in
$45 \mathrm{~mm}$ slices. The depth of these slices shows that the discs were not contributing to the excavation of the chalk. As stated in the paper, the discs were installed to break the larger flints, rather than excavate the chalk.

The cutting action of the picks is driven mainly by the torque on the cutterhead, although some contact force will also be required. Although the contact force was relatively consistent throughout the drive, the torque, as shown in Figure 11(b), increased significantly over the drive, excluding the area of the pingo. Do the authors consider that this increase in torque reflected changing ground conditions, or cumulative wear of the TBM and the cutting tools?

The authors have summarised individual TBM parameters, but not tried to combine those parameters; the discussion contributor has found, in stronger rocks, that combinations of parameters (Shirlaw, 2016) can be useful in assessing the nature of the ground being excavated. For the Lee Tunnel, in weak rock, the assessment of the specific energy along the alignment might provide additional information on the tunnelling and the ground conditions encountered. For example, Purwodihardjo et al. (2011) were able to correlate changes in lithology with changes in specific energy for the CLEM7 tunnel in Brisbane.

\section{Author's reply}

The authors would like to thank the discussion contributor for the interest shown in the performance of the Lee Tunnel TBM and for drawing on experience from similar tunnelling projects. In response to the discussion raised, a number of important TBM details are clarified, such as its limiting maximum thrust of $84446 \mathrm{~N}$ and a ring length of $1.70 \mathrm{~m}$, in addition to confirming the respective excavated diameter and limiting torque of the cutterhead of $8.85 \mathrm{~m}$ and $8597 \mathrm{kNm}$ that are already on the Herrenknecht website.

The authors are of the opinion that there is strong evidence to indicate that the roller discs contributed to most of the cutting action, as seen in the strong score marks in the chalk tunnel face during TBM head interventions. 
Furthermore, 80 worn roller discs were replaced over the duration of the tunnel drive. The initial set of 88 chisel picks were replaced very early in the drive, as flint damage due to impact had been observed. Once the new bullet picks were fitted, none were then changed for the duration of the drive and they showed very little wear when the TBM was lifted out of the reception shaft. It is believed that the roller discs broke the chalk into chips (a typical characteristic of cutterhead excavation in rock) and that the picks did most of the excavation work when in the relatively short sections of softer ground (i.e. the pingo structure and Thanet Sand in the Plaistow graben).

From the geological model, it can be seen that, with the exception of the Plaistow graben and pingo geological structures, the ground conditions remained relatively consistent through Ciria A grade Haven Brow and Cuckmere beds. Instead, the authors believe that the increase in torque is a reflection of the TBM drivers becoming more familiar with the ground and, more significantly, the TBM's limiting factors. This is in tandem with the increase in cutting wheel power, front thrust, front contact force and, significantly, advance speed, as shown in Figure 11(a), which indicate the increase in confidence of the machine and ground.
Although no attempt has been made to assess a combined energy output per se, the authors feel that there has been an adequate comparative assessment of TBM parameters, particularly within Sections 4.2, 4.4 and 4.5; for example, where readings from a number of parameters have been used to assess the TBM performance on approach to the Plaistow graben and pingo geological structures.

\section{REFERENCES}

Bruland A (2000) Hard Rock Tunnel Boring, The Boring Process. Vol. 7 of $10 . \mathrm{PhD}$ thesis, Norwegian University of Science and Technology (NTNU), Trondheim, Norway.

Newman T, Bellhouse M, Corcoran J, Sutherden R and Karaouzene R (2016) TBM performance through the engineering geology of the Lee Tunnel. Proceedings of the Institution of Civil Engineers Geotechnical Engineering 169(3): 299-313, http://dx.doi.org/ 10.1680 /jgeen. 15.00133

Purwodihardjo A, McQueen L, Barrett S and Booth P (2011) Effects of ground conditions on hard rock TBM performance, CLEM7 tunnel, Brisbane, case history. Proceedings of the World Tunnel Congress (WTC), Helsinki, Finland.

Rostami J, Ozdemir L and Nilsen B (1996) Comparison Between CSM and NTH Hard Rock TBM Performance Prediction Models. Institute of Shaft Drilling Technology, Las Vegas, NV, USA.

Shirlaw JN (2016) Pressurised TBM tunnelling in mixed face conditions resulting from tropical weathering of igneous rock. Tunnelling and Underground Space Technology 57: 225-240, https://doi.org/10. 1016/j.tust.2016.01.018. 